\title{
CORRECTION
}

\section{Correction to: Enhanced mechanical strength of talc-containing porous kaolin prepared by a replica method}

\author{
Sujin Lee ${ }^{1}$ Jang-Hoon $\mathrm{Ha}^{1}\left[\right.$ ] $\cdot$ Jongman Lee ${ }^{1} \cdot$ In-Hyuck Song ${ }^{1}$
}

Published online: 16 September 2020

(c) The Korean Ceramic Society 2020

Correction to: Journal of the Korean Ceramic Society https://doi.org/10.1007/s43207-020-00073-6

During the copyediting process, the author given and family names have been swapped. They should be read as follows:

Sujin Lee

Jang-Hoon Ha

Jongman Lee

In-Hyuck Song

The original article can be found online at https://doi.org/10.1007/ s43207-020-00073-6.

Jang-Hoon Ha

hjhoon@kims.re.kr

1 Powder and Ceramics Division, Korea Institute of Materials

Science, 797 Changwondaero, Seongsan-gu, Changwon,

Gyeongsangnam-do 51508, Republic of Korea 